\title{
Acute Cognitive Effects of Physical Activity for People who have Dementia
}

\author{
Jordan Elliott-King ${ }^{1 *}$, Elizabeth Peel ${ }^{2}$ and Eef Hogervorst ${ }^{3}$ \\ ${ }^{1}$ Faculty of Health and Society, University of Northampton, Northampton, UK \\ ${ }^{2}$ School of Social Sciences and Humanities, Loughborough University, Loughborough, UK \\ ${ }^{3}$ School of Sport, Exercise and Health Sciences, Loughborough University, Loughborough, UK \\ *Corresponding author: Jordan Elliott-King, School of Sport, Exercise and Health Sciences, National Centre for Sport and \\ Exercise Medicine, Loughborough University, Loughborough, LE11 3TU, UK, Tel: 01509-223020
}

\begin{abstract}
Background: Physical activity has the potential to improve cognition for those with dementia, as demonstrated by randomised controlled trials lasting at least 6 weeks. Research is yet to explore the acute cognitive effects of physical activity for people with dementia. Acute resistance physical activity with healthy late-middle aged individuals has been shown to facilitate general cognition, as well as benefit executive function specifically. This study therefore aimed to establish if people with dementia experience cognitive benefits from acute resistance physical activity over and above a social control.
\end{abstract}

Methods: A cross-sectional study design was applied to compare resistance physical activity to bingo between 10 participants with dementia to 15 age-matched controls. Following University ethical approval, participants were recruited from Alzheimer's or dementia activity and support groups held in the community. Acute cognitive effects were assessed using the Mini Mental Status Examination (MMSE), Hopkins Verbal Learning Test (HVLT), Verbal Fluency (VF) and The Cognitive Computerised Test Battery for Individual's with Intellectual Disabilities (CCIID); before and after a short bout of seated resistance band physical activity or a social control, bingo. The participants then completed the opposing activity 6 weeks later, and then cognitive assessments alone a further 6 weeks later. This allowed to analyse cognitive effects immediately and 6 weeks after. Statistical analysis included Mann Whitney $U$ test, Chi-square test and Mix-measured ANOVA to compare scores across time-points.

Results: Participants had a mean age of 76 years, $40 \%$ were male and $60 \%$ were female. For participants with dementia immediately after the resistance band activity improvements can be observed on the MMSE, VF, HVLT, Series, Jigsaw and Total CCIID. Only the MMSE, Series and
Total CCIID still showed improvements at 6-weeks followup. Immediately following the psychosocial intervention, participants with dementia only showed improvements on the HVLT, which were not sustained after 6-weeks. For agematched controls, bingo appeared to be more beneficial than physical activity.

Conclusion: These results indicate that there are differential acute effects of activity depending upon pre-existing cognitive ability. Specific cognitive benefits may be available for people with dementia following resistance band physical activity. This pilot study shows promising indications for physical activity as a therapy for dementia, however results should be interpreted with caution due to the small sample size of this study.

\section{Keywords}

Dementia, Alzheimer's disease, Exercise, Physical activity, Cognition, Cognitive effects

\begin{abstract}
Abbreviations
MMSE: The Mini Mental Status Examination; HVLT: Hopkins Verbal Learning Test; VF: Verbal Fluency; CCIID: The Cognitive Computerised Test Battery for Individual's with Intellectual Disabilities
\end{abstract}

\section{Introduction}

The onset and progression of dementia is characterised by cognitive decline. Treatments should therefore aim to alleviate the effects of cognitive decline. Traditional treatment is sought through pharmacology. When successful, available treatments are only able to slow cognitive decline for a short period of time; no research has supported the use of current pharmacological ther- 
apies longer term [1]. This is because currently there are no pharmacological treatments available that are disease modifying. Treatment strategies that have sought to act directly upon the disease, such as acetylcholinesterase inhibitor drugs, have so far been unsuccessful due to their poor solubility, lower bioavailability, and ineffective ability to cross the blood-brain barrier [2]. Pharmacological treatments are therefore limited to therapies that alleviate the symptoms of dementia. Antipsychotic agents are widely used to reduce the neuropsychiatric symptoms and people with dementia represent a large portion of the antipsychotics prescribed in UK primary care [3]. However, the evidence regarding antipsychotics for symptom management is controversial due to limited efficacy, the risk for serious adverse events [4] and the introduction of an abundance of undesirable side-effects [5]. It is therefore imperative to utilise treatments either in combination with - or independently of - pharmacology that could further prolong the maintenance of cognitive functioning for people with dementia.

Physical activity interventions have been shown to provide numerous benefits for people with dementia. Interventions often involve taking part in physical activity three to five times per week, for at least a twoweek period, with some interventions continuing for up to 6 months [6]. The most widely recognised physical benefits of physical activity are those observed by increasing cardiovascular and cardiorespiratory fitness [7]. Research has further evidenced increases in balance, mobility, functional ability, performance of activities of daily living, flexibility, agility and muscle strength, as well as reduced concern for falls and physical abilities [8-11].

Beyond the well-known physical effects of engaging with physical activity long term, research has shifted emphasis to the cognitive benefits resulting from physical activity engagement. A meta-analysis found that physical activity programs lasting between 6 and 52 weeks had an overall positive effect on global cognitive function of people with dementia [12]. This effect was shown regardless of the type of dementia diagnoses and whether the physical activity was high or low frequency, it was most pertinent for combined physical activity programs and aerobic based programs. Programs combining physical activity and cognitive stimulation have been found to benefit global cognitive functioning of older adults with dementia [13] and may be more beneficial than physical activity by itself [14]. Specific benefits of physical activity have also been shown for attention, processing speed, executive functions, memory and conflict resolution [15-18]. It is for these reasons that physical activity is frequently recommended as a treatment for dementia [19].

Reviews have most prominently shown positive effects for aerobic only physical activity programs [12] (e.g. Groot, et al. 2016). However, several more recent studies have highlighted cognitive benefits of strength or resistance activities, a common form of non-aerobic physical activity. For example, Mavros and colleagues [20] found high intensity progressive resistance training resulted in significant improvements in cognitive function, with strength gains mediating the cognitive benefits of resistance training [20]. Strength promoting physical activity advocated in guidelines has been supported by Health Survey data for England and Scotland over and above generic physical activity recommendations [21]. Furthermore, resistance based physical activity has been shown to be feasible, easy for staff to administer and requires minimal equipment [22,23]; as well as being tolerated well and enjoyed by older adults [24]. This indicates that resistance based physical activity may be feasible as a potential therapy for people with dementia. Additionally, resistance based physical activity can be performed using resistance bands from a seated position, increasing the feasibility and accessibility for individuals of all abilities. This could be advantageous for a therapy aimed at people with dementia, considering dementia frequently co-occurs with frailty impacting the individuals' physical abilities alongside their difficulties resulting from cognitive symptoms [25].

Evidence substantiating the benefits of physical activity over a period of at least six weeks for people with dementia is pervasive. Research into the acute or immediate effects of physical activity for people with dementia, however, is sparse. Current literature does suggest that a single bout of physical activity can alter an individual's cognitive performance $[26,27]$. The benefits observed from a single session of aerobic activity, specifically, has been observed across various cognitive functions, including attention, information processing, memory and executive functions [28-30]. It has been further suggested that the influence of physical activity on higher order cognition is affected by ceiling effects; therefore, participants with low performance on executive function tasks can expect the greatest benefits from a single session of physical activity [31-33]. For that reason, it can be expected that people with dementia are likely to experience acute cognitive effects from physical activity, especially on executive tasks.

Although the positive effects of physical activity are well documented, evidence for the underlying biological mechanisms remains limited. Acute physical activity has been suggested to induce numerous molecular and cellular processes that support brain plasticity and general brain health [34]. For instance, physical activity has been shown to enhance neurogenesis $[35,36]$ specifically in the hippocampus [37], increase neurotrophin concentrations [34,38], increase blood flow throughout the vascular system (also termed vascularisation) $[39,40]$ and finally, reduce the effects of neuroinflammation [41].

Research has further indicated that physical activ- 
ity can lead to longer term benefits on brain health. For example, meta-analysis has shown links between physical activity levels and white matter structure [42], the prevention of prefrontal volume reduction [43], as well as age-related hippocampal deterioration [44]. Despite consensus from both animal and human studies that physical activity benefits brain function, further research is needed to establish the exact neurobiological mechanisms that mediate the benefits of physical activity on cognition, behaviour and neurodegenerative diseases [45]. Having said that, based on this varying assemblage of mechanisms that indicate improvement through engagement in physical activity, researchers have suggested that physical activity is able to positively affect people with dementia through brain vitality in general rather than dementia specific pathological mechanisms [12].

Considering the potential for physical activity to improve brain health of people with dementia and as a result mitigate the effects of characteristic cognitive decline, the cognition should be measured following a short bout of physical activity to better understand the potential for physical activity to act as a therapy for dementia. Previous physical activity studies have applied various cognitive assessments to measure the effects of the physical activity programs. The Mini Mental State Examination or MMSE [46], for instance, has been used to compare cognitive scores of people with dementia before and after both aerobic [47] and combined physical activities [48]. Toots and colleagues applied both the MMSE and the Verbal Fluency or VF [49] to their research into high intensity strength and balance training for people with dementia but did not find significant differences between groups using these tests [50]. Earlier research by Steinberg, Leoutsakos, Podewils and Lyketsos [51] also used the Hopkins Verbal Learning Test or HVLT [52] to assess the effects of combined physical activity programs for community dwelling individuals with dementia. The Cognitive Computerised Test Battery for Individual's with Intellectual Disabilities or CCIID [53], on the other hand, is yet to be utilised within this context. However, considering the CCIID's accuracy in detecting diagnoses of dementia for previously healthy individuals, as well as those with a pre-existing intellectual disability [54,55], there is potential that the CCIID could also be sensitive to acute cognitive changes resulting from physical activity engagement. The aims of this study are hence twofold; to firstly, establish the acute cognitive effects of a short bout of physical activity for people with dementia and aged-matched controls; and secondly, establish whether physical activity shows cognitive benefits over and above a psycho-social control activity on a new assessment of executive functioning (the CCIID) and other cognitive assessments previously shown to be sensitive to effects of physical activity in dementia.

\section{Methods}

\section{Participants and procedure}

Once ethical approval was given by Loughborough University ethical committee, participants were recruited from Alzheimer's disease or Dementia activity groups local to Loughborough University. In total, 25 individuals took part in the study, 10 who self-reported that they had been diagnosed with dementia and 15 were aged-matched controls. Participants were all educated at secondary school level or higher, identified as British or white British and were of a medium to high socioeconomic status. Participants were invited to 3 sessions at Loughborough University, with 6 weeks between each session. Participants came to each session as a pair, i.e. carers accompanied people with dementia and both took part. Sessions started at 9:30 am on a weekday morning. Upon arriving all participants completed a cognitive assessment. Cognitive assessments utilised included the Mini-Mental Status Examination (MMSE) [46] followed by the Hopkins Verbal Learning Test (HVLT) [52], Verbal Fluency (VF) [49] and The Cognitive Computerised Test Battery for Individual's with Intellectual Disabilities (CCIID) [53]. The cognitive assessments applied during the study were completed in the same order each time but with different versions of the instruments utilised where possible. Participants were then offered a drink and had a chat with the researchers. The participants would then complete 30 minutes of a social activity or 30 minutes of resistance band physical activity. The activities were order-balanced so each couple would complete either a social activity and then the physical activity, or vice versa. Immediately following both activities all participants would complete a second cognitive assessment. The third and final session was one cognitive assessment as a 6-weeks follow-up to the previous activity, but no activities were undertaken during this session.

\section{Intervention}

The activities took 30 minutes each. Two researchers and 2 participants were present for all activity sessions. Social interaction was controlled for throughout. Researchers ensured that social interaction was encouraged, this ensured all participants were equally engaged with conversation throughout both activities. The psychosocial control activity involved a group of four people playing a game of bingo while seated at a table. One researcher called the numbers and the other three individuals participated in the game of bingo. Each player was given two bingo cards and the games lasted around 30 minutes each time. Table 1 shows the timeline of the interventions and assessments that participants completed.

The resistance band physical activity condition contained four activities. Each activity required participants to be seated, with each end of the resistance 
Table 1: Intervention timeline.

\begin{tabular}{|l|l|l|l|l|l|}
\hline $\begin{array}{l}\text { Participant } \\
\text { assigned to: }\end{array}$ & Timepoint 1 & Timepoint 2 & Timepoint 3 \\
\hline Group 1 & $\begin{array}{l}\text { Baseline cognitive assessments, } \\
\begin{array}{l}\text { 30 minutes of psychosocial } \\
\text { intervention (bingo), immediate } \\
\text { cognitive effects assessed. }\end{array}\end{array}$ & $\begin{array}{l}\text { 6 weeks in } \\
\text { between }\end{array}$ & $\begin{array}{l}30 \text { minutes of resistance } \\
\text { band physical activity, } \\
\text { immediate cognitive effects } \\
\text { assessed. }\end{array}$ & $\begin{array}{l}\text { 6 weeks in } \\
\text { between }\end{array}$ & $\begin{array}{l}\text { Cognitive } \\
\text { assessment follow } \\
\text { up with no activity }\end{array}$ \\
\hline Group 2 & $\begin{array}{l}\text { Baseline cognitive assessments, } \\
\text { 30 minutes of resistance band } \\
\text { physical activity, immediate } \\
\text { cognitive effects assessed. }\end{array}$ & $\begin{array}{l}\text { OR weeks in } \\
\text { between }\end{array}$ & $\begin{array}{l}30 \text { minutes of psychosocial } \\
\text { intervention (bingo), } \\
\text { immediate cognitive effects } \\
\text { assessed. }\end{array}$ & $\begin{array}{l}6 \text { weeks in } \\
\text { between }\end{array}$ & $\begin{array}{l}\text { Cognitive } \\
\text { assessment follow } \\
\text { up with no activity }\end{array}$ \\
\hline
\end{tabular}

band to be held firmly in each hand, with the middle of the band tucked underneath the middle of both of the participant's feet. Researchers checked the band had been placed correctly to guarantee safety when beginning the activity, if the band was not correctly centred under the feet. participants were asked to adjust this appropriately before receiving any further instruction. The first task asked participants to rotate their core while holding the band tightly to their side. This activates their core or trunk muscles [56], which includes both the abdominal and paraspinal muscles, which have been shown to play a crucial role in maintaining balance and functional mobility in older adults [57].

Additionally, findings from Rogers and Jarrott [58] indicated that upper body muscle strength is both associated with dementia and a key contributor to functional disability. The second and third activities therefore activated the muscles in the arms and shoulders as a way of building strength in the upper body. Arm muscle strength is also crucial for many activities of daily life, such as eating and drinking. Specifically, the second activity asked the participants to put their arms straight down by their side, then slowly extending them out to the side. The third asked the participants to maintain the band in the same position under their feet but switch the hands in which they were holding the bands; this created a cross in the band in front of the participants' knees.

Participants were then asked to pull the band up towards their chest, while sticking their elbows out in a movement akin to rowing a boat. Leg strength could also be crucial for activities of daily living, playing a role in important activities such as walking, getting up and down from a chair, climbing stairs. Increases in leg strength have been significantly associated with increases in walking endurance in older adults [59].

Therefore, the final activity participants were asked to perform with the resistance bands activated the leg muscles. Specifically, the participants were required to 'uncross the band' or switch the hands in which they were holding the band and remove one foot from the band, so that the band looped round only one of the participants' feet this time. The participants were then asked to pull their knee up toward their chest while keeping the band held tightly and their arms still, this was followed by stretching their legs out towards the floor and away from their chairs. This was repeated for both legs. Each part of the physical activity was completed a minimum of 4 or 5 times, as researchers and participants were talking continuously however, number of repetitions were not strictly counted, just as long as participants felt the physical response from engaging with the resistance band this was deemed sufficient repetitions. All four components of the activity were then repeated at least one more time. This in total took around 30 minutes to complete.

\section{Statistical analysis}

Analyses were conducted in SPSS version 24.0. Firstly, Descriptive Statistics, Mann Whitney U and Chisquare analysis were conducted. Means and standard deviations of each of the cognitive scores were then examined across all three time-points, before, after and at 6-weeks follow-up. Boxplots were then created to further examine mean differences following each intervention. Mixed effect measures $3 \times 2 \times 2$ ANOVA were applied to investigate if there was a significant difference in the interaction of two within subject measures, "time" and "intervention" and the between subjects "group" factor.

\section{Results}

Table 2 shows baseline demographic information for all participants. The groups did not differ significantly in age or gender. All cognitive assessments and instrumental activities of daily living showed significant differences between participants with dementia and controls. Participants did not, however, differ in scores on the physical self-efficacy questionnaire or the Geriatric Depression Scale. None of the participants scored below 6 on the GDS, the suggested cut-off that could indicate a depression [60].

Cognitive scores were then examined across all three time-points of each intervention. Table 3 shows these means and standard deviations. For participants with dementia immediately after the resistance band activity improvements can be observed on the MMSE, VF, HVLT, Series, Jigsaw and Total CCIID. Only the MMSE, Series and Total CCIID still showed improve- 
Table 2: Baseline participant information.

\begin{tabular}{|c|c|c|c|c|}
\hline Characteristic & $\begin{array}{l}\text { People with } \\
\text { dementia }\end{array}$ & Controls & Total sample & $\begin{array}{l}\text { Mann Whitney } U \text { or } X_{2} \\
\text { statistic, } P \text { value }\end{array}$ \\
\hline $\mathbf{N}$ & 10 & 15 & 25 & - \\
\hline Age mean \pm SD & $78.78(8.91)$ & $74.47(9.79)$ & $76.08(9.514)$ & $U=50.50, p=0.310$ \\
\hline Gender male n (\%): female n (\%) & $7(70 \%): 3(30 \%)$ & $3(20 \%): 12(80 \%)$ & $10(40 \%): 15(60 \%)$ & $X_{2(1)}=1.00, p=0.317$ \\
\hline MMSE mean \pm SD & $18.44(6.84)$ & $28.71(1.44)$ & $24.70(6.67)$ & $U=5.00, p \leq 0.001^{* *}$ \\
\hline VF mean \pm SD & $9.22(8.27)$ & $20.93(5.37)$ & $16.35(8.72)$ & $U=16.00, p=0.003^{* *}$ \\
\hline HVLT mean \pm SD & $7.6(6.62)$ & $24.14(6.59)$ & $17.25(10.54)$ & $U=7.00, p \leq 0.001^{* *}$ \\
\hline Series mean \pm SD & $14.25(10.73)$ & $30.64(8.81)$ & $23.74(12.53)$ & $U=10.00, p=0.005^{\star *}$ \\
\hline Odd One Out mean \pm SD & $24.25(9.69)$ & $34.91(8.26)$ & $30.42(10.18)$ & $U=13.50, \mathbf{p}=\mathbf{0 . 0 1 2 ^ { * * }}$ \\
\hline Jigsaw mean \pm SD & $3.67(2.34)$ & $9.11(4.78)$ & $6.93(4.76)$ & $U=6.50, \mathbf{p}=\mathbf{0 . 0 1 5 ^ { * }}$ \\
\hline Total CCIID mean \pm SD & $41.25(22.15)$ & $73.00(19.38)$ & $59.63(25.67)$ & $U=8.50, p=0.003^{* *}$ \\
\hline Physical self-efficacy mean \pm SD & $32.00(5.35)$ & $34.62(8.01)$ & $33.48(6.96)$ & $U=47.5, p=0.276$ \\
\hline GDS mean \pm SD & $5.00(3.64)$ & $3.08(2.75)$ & $3.90(3.22)$ & $U=35.5, p=0.185$ \\
\hline Carer Strain mean \pm SD & - & $14.44(4.77)$ & - & - \\
\hline IADL mean \pm SD & $16.25(3.45)$ & $26.00(0.00)$ & $21.41(5.51)$ & $U=0.00, p \leq 0.01^{* *}$ \\
\hline
\end{tabular}

"Indicates a significant result ( $p \leq 0.05)$; " Indicates a significant result $\left(p \leq 0.01^{* *}\right)$.

Table 3: Means and standard deviations of cognitive scores across time-points.

\begin{tabular}{|c|c|c|c|c|c|}
\hline \multirow{2}{*}{ Assessment } & \multirow{2}{*}{ Time-point } & \multicolumn{2}{|c|}{ Physical activity intervention mean (SD) } & \multicolumn{2}{|c|}{ Psychosocial intervention mean (SD) } \\
\hline & & Dementia & Controls & Dementia & Controls \\
\hline \multirow{3}{*}{ MMSE } & Before & $18.14(7.73)$ & $28.82(1.54)$ & $19.29(7.16)$ & $27.91(2.17)$ \\
\hline & Immediately after & $18.86(6.01)$ & $28.45(1.51)$ & $19.71(7.91)$ & $27.72(2.24)$ \\
\hline & 6 weeks after & $19.57(6.70)$ & $28.82(1.17)$ & $19.71(8.04)$ & $28.18(2.32)$ \\
\hline \multirow{3}{*}{ VF } & Before & $9.71(9.38)$ & $20.09(5.34)$ & $9.86(8.91)$ & $22.18(7.81)$ \\
\hline & Immediately after & $10.00(7.42)$ & $22.27(2.83)$ & $7.71(4.54)$ & $21.82(4.14)$ \\
\hline & 6 weeks after & $8.57(6.55)$ & $22.55(8.12)$ & $10.71(9.25)$ & $21.09(6.77)$ \\
\hline \multirow{3}{*}{ HVLT } & Before & $8.57(7.04)$ & $24.36(5.35)$ & $9.00(8.08)$ & $22.55(5.43)$ \\
\hline & Immediately after & $9.00(7.37)$ & $22.91(4.93)$ & $11.43(9.38)$ & $22.09(4.83)$ \\
\hline & 6 weeks after & $8.86(7.54)$ & $23.82(6.51)$ & $8.43(7.07)$ & 24.09 (5.34) \\
\hline \multirow{3}{*}{ Series } & Before & $16.67(11.25)$ & $30.38(5.97)$ & $18.17(9.11)$ & $27.50(7.56)$ \\
\hline & Immediately after & $19.33(9.93)$ & $33.00(4.31)$ & $14.17(9.70)$ & $29.88(9.20)$ \\
\hline & 6 weeks after & $20.50(11.31)$ & $27.25(7.56)$ & $17.50(12.63)$ & $32.00(6.30)$ \\
\hline \multirow{3}{*}{000} & Before & $26.83(8.40)$ & $32.63(8.03)$ & $30.00(7.40)$ & $33.25(8.84)$ \\
\hline & Immediately after & $26.67(9.20)$ & $33.25(4.13)$ & $29.83(7.08)$ & 32.75 (8.22) \\
\hline & 6 weeks after & 27.33 (7.94) & 33.88 (5.33) & $23.83(11.51)$ & 32.75 (8.26) \\
\hline \multirow{3}{*}{ Jigsaw } & Before & $1.50(0.71)$ & 8.14 (3.39) & $2.00(1.41)$ & 7.28 (3.90) \\
\hline & Immediately after & $2.00(1.41)$ & $7.14(4.10)$ & $1.50(2.12)$ & $7.29(4.27)$ \\
\hline & 6 weeks after & $2.00(1.41)$ & $8.86(2.67)$ & $2.00(1.41)$ & $7.43(4.35)$ \\
\hline \multirow{3}{*}{ Total CCIID } & Before & $47.17(21.36)$ & $70.88(14.24)$ & $53.17(16.92)$ & $67.63(17.29)$ \\
\hline & Immediately after & 48.17 (20.88) & $72.50(10.14)$ & $45.83(15.94)$ & 69.75 (16.93) \\
\hline & 6 weeks after & $53.50(18.51)$ & 69.38 (14.36) & $44.17(26.77)$ & $75.50(11.80)$ \\
\hline
\end{tabular}

ments at 6-weeks follow-up. Immediately following the psychosocial intervention, participants with dementia only showed improvements on the HVLT, which were not sustained after 6 -weeks. For age-matched controls acute effects of resistance band activity were observed on the VF, Series, Odd One Out and Total CCIID. None of these scores continued to improve at 6 weeks follow-up. Improvements in the Series and Total CCIID cognitive scores were observed for people without dementia immediately following the psychosocial intervention.

Boxplots were then utilised to visually examine any changes in means resulting from each intervention. Figure 1 shows the HVLT scores of people with dementia before, after and 6 weeks after each intervention. 


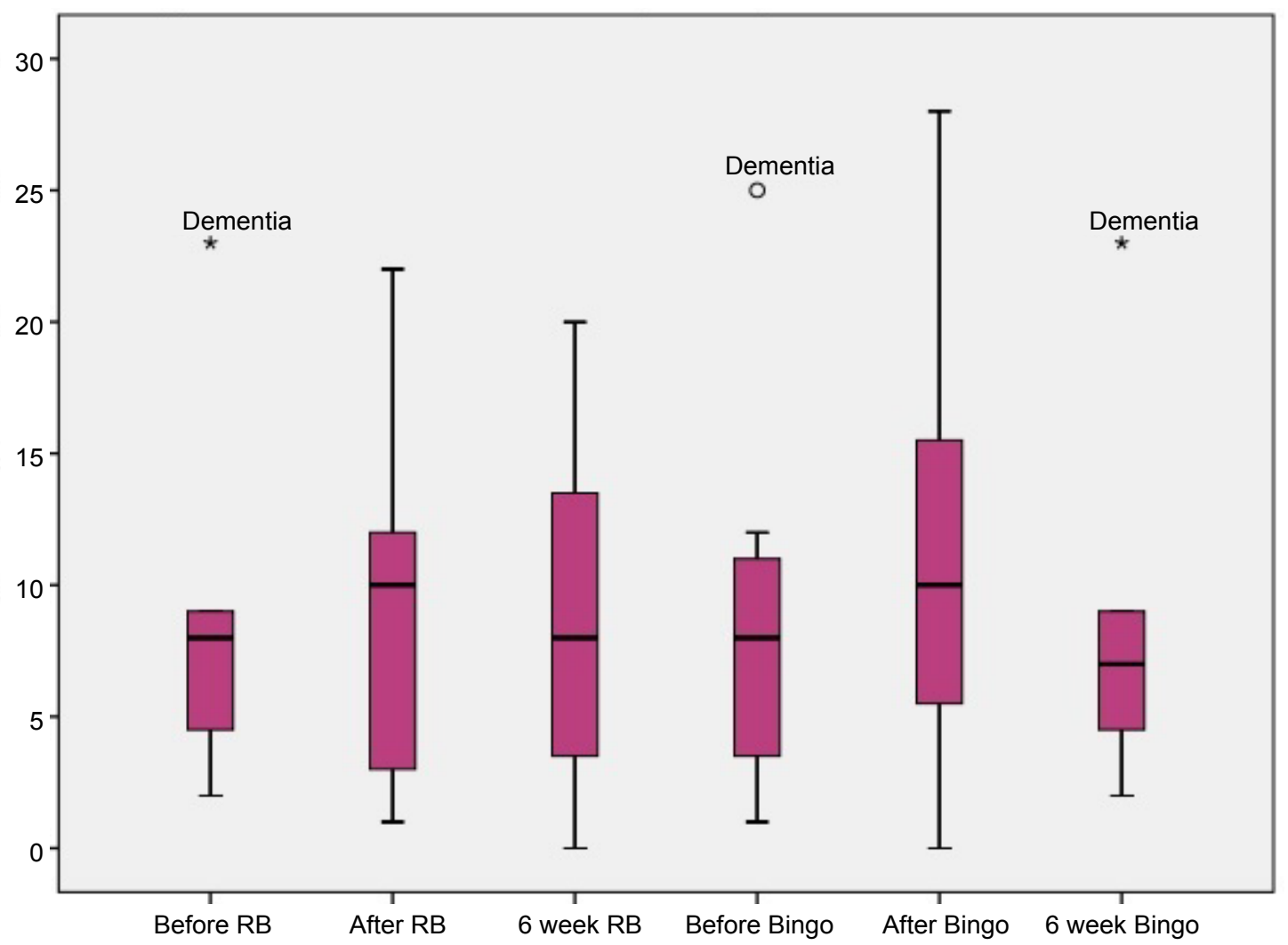

Figure 1: HVLT scores for participants with dementia.

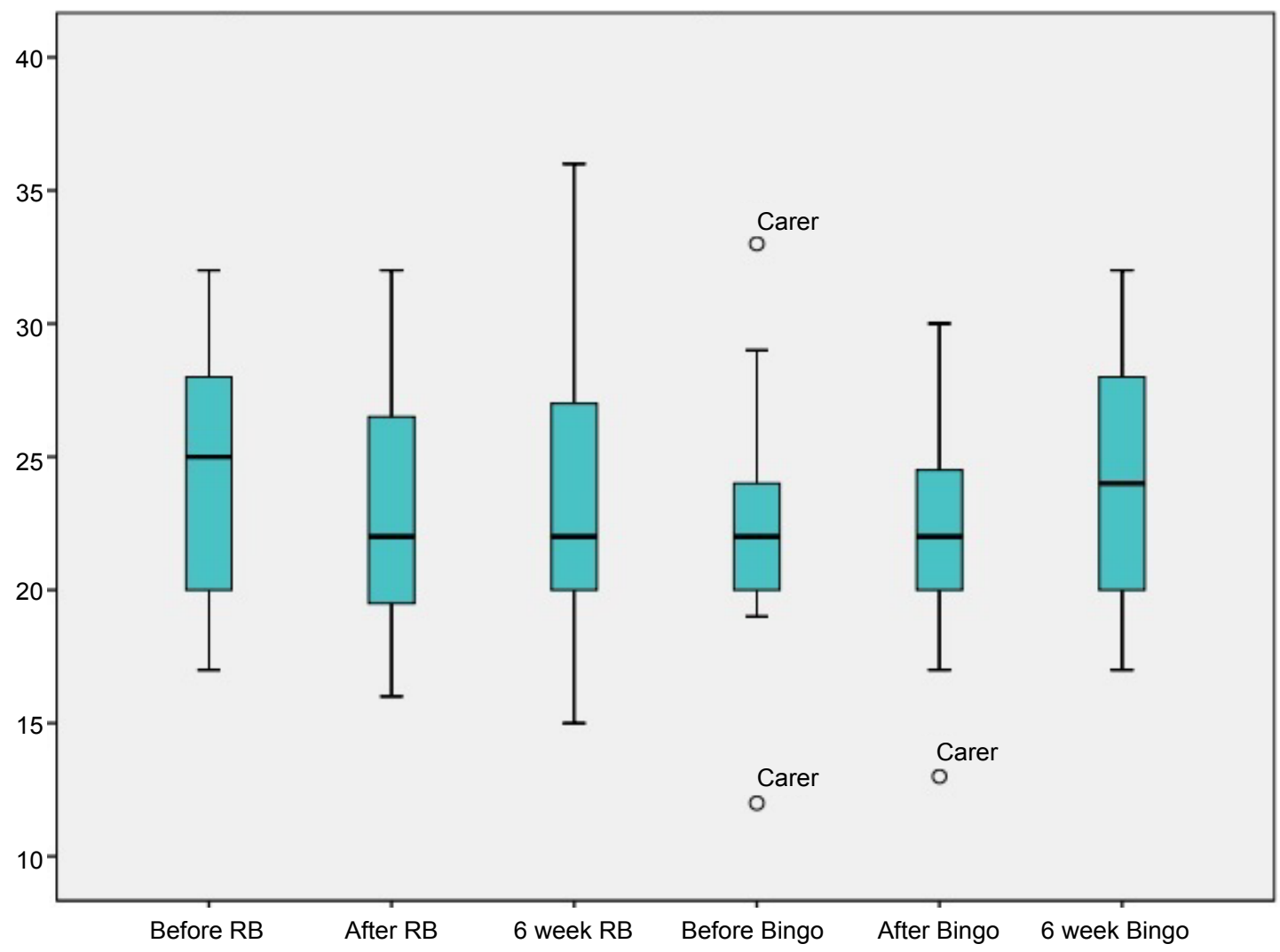

Figure 2: HVLT scores for age-matched controls.

An increase on the HVLT immediately following the resistance band physical activity can be observed and a slight increase on the psychosocial intervention too. These improvements, however, were not maintained at
6 weeks follow-up.

On the other hand, age-matched controls experienced a decline in HVLT scores immediately following the resistance bands and stayed the same following the 
psychosocial intervention, as shown in Figure 2. Participants suggested through comments to the research that they were experiencing tiredness effects. This could have influenced participant's cognitive scores for age-matched controls over and above intervention effects.

Figure 3 shows the CCIID Series subtest scores for participants with dementia before, after and 6 weeks

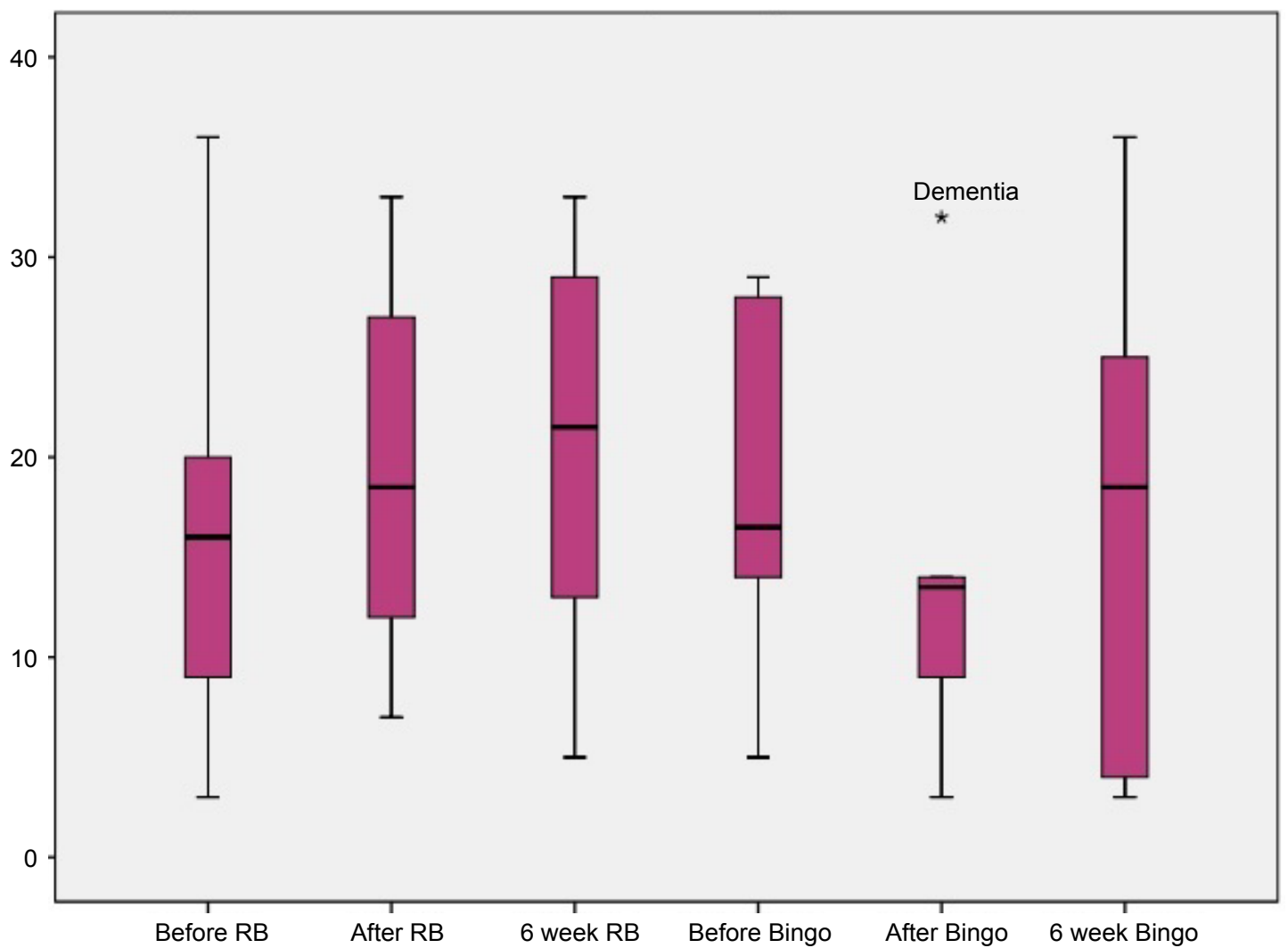

Figure 3: Series scores for participants with dementia.

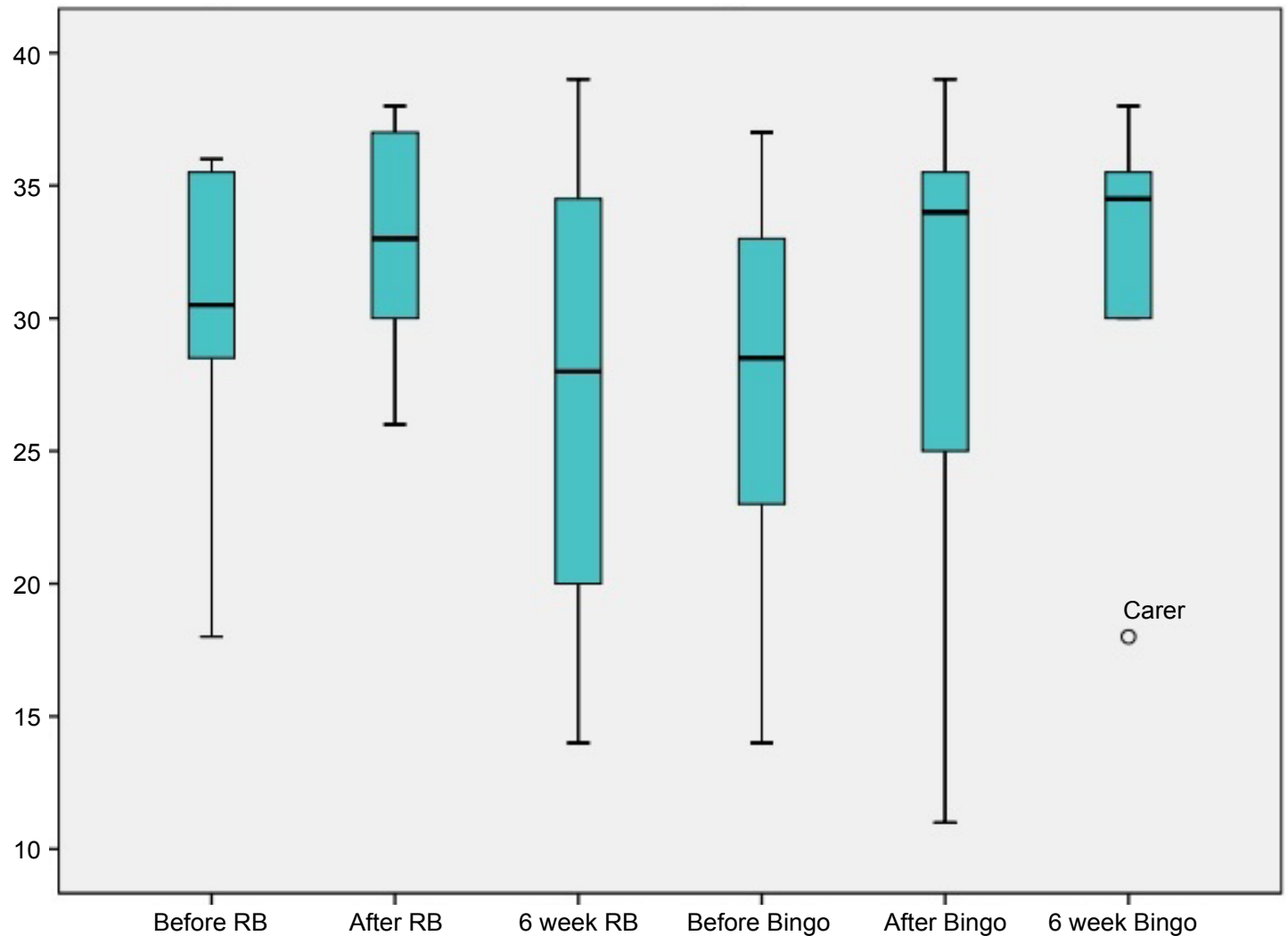

Figure 4: Series scores for age-matched controls. 
after both physical and psychosocial interventions. Here the Series scores can be observed to increase following the physical intervention, whereas a decrease can be observed declining immediately following the psychosocial control activity.

Figure 4 shows the Series scores for participants without dementia before, after and 6 weeks after both interventions. It can be observed that both interventions result in a slight increase in Series scores.

Following inspection of the means, a mixed-measures $3 \times 2 \times 2$ ANOVA was used to investigate whether there was a significant difference between "time", "intervention" and "groups". As shown in Table 4, the MMSE, VF, HVLT, Series and Total CCIID all showed significant group differences. The HVLT showed a significant time by group effect. Trends towards significance were also shown in overall interaction effect of time, intervention and group for the Series and Total CCIID; indicating that with sufficient power, the Series and total CCIID could have detected significant interaction effects.

\section{Discussion}

The present study indicated that there could be cognitive benefits of physical activity for people with de- mentia over and above a psychosocial control activity. Increase in cognitive scores were visible on the MMSE, VF, HVLT, Series and Jigsaw subtests and total CCIID immediately after engaging in a short bout of resistance band physical activity. Acute effects following the psychosocial control activity were only observable on the HVLT for people with dementia. Both interventions offered social interaction, therefore these results suggest that greater benefits could be available to people with dementia through engagement in physical activity with others, rather than just engaging in a psychosocial activity. Interestingly, the effects differed slightly for those without dementias, who showed cognitive improvements on the VF, Series, Jigsaw and Total CCIID following the physical activity, but following the psychosocial control activity only on the Series and Total CCIID. These findings are consistent with previous work that indicated that a single bout of physical activity can have acute cognitive benefits [26].

The results also suggested a greater benefit of physical activity for people with dementia than age-matched controls. Specifically, previous studies have found that the influence of physical activity engagement on higher order cognitive functions is affected by ceiling effects. This means that participants with lower baseline

Table 4: Mixed measures three-way Anova effects.

\begin{tabular}{|c|c|c|c|c|c|c|c|}
\hline $\begin{array}{l}\text { ive } \\
\text { ments }\end{array}$ & Group & ntervention & Time & & Time $^{*}$ group & & \\
\hline$M S C$ & $\begin{array}{l}F_{(1,16)}=18.05 \\
p \leq 0.001^{*} \\
n^{2}=0.53\end{array}$ & $\begin{array}{l}\mathrm{F}_{(1,16)}=0.002, \\
\mathrm{p}=0.964 \\
n^{2}=0.00\end{array}$ & $\begin{array}{l}\mathrm{F}_{(2,32)}=1.811, \\
\mathrm{p}=0.180 \\
n^{2}=0.10\end{array}$ & $\begin{array}{l}F_{(1,16)}=2.485 \\
p=0.135 \\
n^{2}=0.13\end{array}$ & $\begin{array}{l}\mathrm{F}_{(2,32)}=1.343 \\
\mathrm{p}=0.275 \\
n^{2}=0.08\end{array}$ & $\begin{array}{l}F_{(2,32)}=0.100 \\
p=0.905 \\
n^{2}=0.01\end{array}$ & $\begin{array}{l}F_{(2,32)}=0.269, \\
p=0.766, \\
n^{2}=0.02\end{array}$ \\
\hline VF & $\begin{array}{l}F_{(1,16)}= \\
17.176 \\
p \leq 0.001^{*} \\
n^{2}=0.52\end{array}$ & $\begin{array}{l}\mathrm{F}_{(1,16)}=0.004 \\
\mathrm{p}=0.950 \\
n^{2}=0.00\end{array}$ & $\begin{array}{l}\mathrm{F}_{(2,32)}=0.061 \\
\mathrm{p}=0.941 \\
n^{2}=0.00\end{array}$ & $\begin{array}{l}F_{(1,16)}=0.004 \\
p=0.950 \\
n^{2}=0.00\end{array}$ & $\begin{array}{l}\mathrm{F}_{(2,32)}=0.516 \\
\mathrm{p}=0.602 \\
n^{2}=0.03\end{array}$ & $\begin{array}{l}\mathrm{F}_{(2,32)}=1.205 \\
\mathrm{p}=0.313 \\
n^{2}=0.07\end{array}$ & $\begin{array}{l}\mathrm{F}_{(2,32)}=1.866, \\
\mathrm{p}=0.171, \\
n^{2}=0.10\end{array}$ \\
\hline & $\begin{array}{l}F_{(1,16)}=23.69 \\
p \leq 0.001^{*} \\
n^{2}=0.60\end{array}$ & $\begin{array}{l}F_{(1,16)}=0.001 \\
p=0.980 \\
n^{2}=0.00\end{array}$ & $\begin{array}{l}\mathrm{F}_{(2,32)}=0.094 \\
\mathrm{p}=0.911 \\
n^{2}=0.01\end{array}$ & $\begin{array}{l}F_{(1,16)}=3.59 \\
p=0.076 \\
n^{2}=0.18\end{array}$ & $\begin{array}{l}F_{(2,32)}=3.913 \\
p=0.030^{*} \\
n^{2}=0.20\end{array}$ & $\begin{array}{l}\mathrm{F}_{(2,32)}=0.605 \\
\mathrm{p}=0.552 \\
n^{2}=0.04\end{array}$ & $\begin{array}{l}\mathrm{F}_{(2,32)}=1.121, \\
\mathrm{p}=0.338, \\
n^{2}=0.07\end{array}$ \\
\hline S & $\begin{array}{l}F_{(1,12)}=7.893 \\
p=0.016^{\star} \\
n^{2}=0.40\end{array}$ & $\begin{array}{l}F_{(1,12)}=2.237 \\
p=0.161 \\
n^{2}=0.16\end{array}$ & $\begin{array}{l}F_{(2,24)}=0.994 \\
p=0.385 \\
n^{2}=0.08\end{array}$ & $\begin{array}{l}F_{(1,12)}=1.047 \\
p=0.326 \\
n^{2}=0.08\end{array}$ & $\begin{array}{l}\mathrm{F}_{(2,24)}=3.121 \\
\mathrm{p}=0.062 \\
n^{2}=0.21\end{array}$ & $\begin{array}{l}\mathrm{F}_{(2,24)}=2.170 \\
\mathrm{p}=0.136 \\
n^{2}=0.15\end{array}$ & $\begin{array}{l}F_{(2,24)}=3.024, \\
p=0.067, \\
n^{2}=0.20\end{array}$ \\
\hline Odd & $\begin{array}{l}F_{(1,12)}=2.256 \\
p=0.159 \\
n^{2}=0.16\end{array}$ & $\begin{array}{l}\mathrm{F}_{(1,12)}=0.145 \\
\mathrm{p}=0.710 \\
n^{2}=0.01\end{array}$ & $\begin{array}{l}F_{(2,24)}=1.200 \\
p=0.319 \\
n^{2}=0.09\end{array}$ & $\begin{array}{l}F_{(1,12)}=0.634 \\
p=0.441 \\
n^{2}=0.05\end{array}$ & $\begin{array}{l}F_{(2,24)}=1.989 \\
p=0.159 \\
n^{2}=0.14\end{array}$ & $\begin{array}{l}F_{(2,24)}=1.406 \\
p=0.265 \\
n^{2}=0.11\end{array}$ & $\begin{array}{l}F_{(2,24)}=0.695, \\
p=0.509, \\
n^{2}=0.06\end{array}$ \\
\hline Jigsaw & $\begin{array}{l}F_{(1,7)}=4.727 \\
p=0.066 \\
n^{2}=0.40\end{array}$ & $\begin{array}{l}F_{(1,7)}=0.451 \\
p=0.523 \\
n^{2}=0.06\end{array}$ & $\begin{array}{l}\mathrm{F}_{(2,14)}=0.700 \\
\mathrm{p}=0.513 \\
n^{2}=0.09\end{array}$ & $\begin{array}{l}F_{(1,7)}=0.451 \\
p=0.523 \\
n^{2}=0.06\end{array}$ & $\begin{array}{l}\mathrm{F}_{(2,14)}=0.247 \\
\mathrm{p}=0.784 \\
n^{2}=0.03\end{array}$ & $\begin{array}{l}F_{(2,14)}=0.162 \\
p=0.852 \\
n^{2}=0.02\end{array}$ & $\begin{array}{l}F_{(2,14)}=0.585, \\
p=0.570, \\
n^{2}=0.08\end{array}$ \\
\hline Total CCIID & $\begin{array}{l}F_{(1,12)}=6.87 \\
p=0.022^{*} \\
n^{2}=0.36\end{array}$ & $\begin{array}{l}F_{(1,12)}=0.480 \\
p=0.502 \\
n^{2}=0.04\end{array}$ & $\begin{array}{l}\mathrm{F}_{(2,24)}=0.525 \\
p=0.598 \\
n^{2}=0.04\end{array}$ & $\begin{array}{l}F_{(1,12)}=0.524 \\
p=0.483 \\
n^{2}=0.04\end{array}$ & $\begin{array}{l}\mathrm{F}_{(2,24)}=1.615 \\
\mathrm{p}=0.220 \\
n^{2}=0.12\end{array}$ & $\begin{array}{l}F_{(2,24)}=0.333 \\
p=0.720 \\
n^{2}=0.03\end{array}$ & $\begin{array}{l}F_{(2,24)}=3.119, \\
p=0.062, \\
n^{2}=0.21\end{array}$ \\
\hline
\end{tabular}

*Indicates a significant result $(p \leq 0.05)$; " Indicates a significant result $\left(p \leq 0.01^{* *}\right)$; Italics indicates a trend towards significance. 
performance on executive function tasks, which in this case are the participants with dementia, can expect the greatest benefits from a single session of physical activity $[32,33]$. This was supported by these data.

The three-way mixed ANOVA analysis, although underpowered showed a time by group effect on the HVLT suggesting that differences were observed between people with dementia and those without over each of the three time-points. Furthermore, the Series and Total CCIID showed a trend towards significance on the overall effect of time, group and intervention. This suggests that inductive reasoning could be an executive function that is affected by physical activity engagement. Inductive reasoning has been specifically highlighted as important in the execution of activities of daily living tasks [61]. Therefore, through physical activity engagement people with dementia could increase their inductive reasoning abilities, which could in turn help to maintain their abilities to engage with activities of daily living for longer. This prolongation of independence and activities of daily living could have widespread implications for people with dementia and their families. Literature has advocated home based dementia care as the best option for dementia care moving forward [62]. With around $60 \%$ of people with dementia remaining in the care of familial caregivers at home [63], it is important to encourage the maintenance of activities of daily living and physical activity as a part of dementia care.

The cognitive [12] and physical benefits [7] available to people with dementia through long term engagement with physical activity have been well evidenced throughout the literature. This study highlights the potential for acute benefits from engaging with physical activity and thus further supports the potential for people with dementia to use physical activity as a therapy for dementia in the absence of effective pharmacological treatments [1]. Results from this study, however, should be interpreted with caution as this study was limited by its small sample size. This meant conducted analyses were underpowered. Having said that, the cognitive assessments applied successfully detected subtle cognitive changes resulting from intervention engagement. Previous research has suggested the cognitive assessments applied, specifically the CCIID and the Series subtest, have good potential for clinical use in detecting and diagnosing dementia [55]. This current study indicates further potential for clinical use of the CCIID and Series in assessment of intervention effects.

Considering the well documented cognitive benefits available to people with dementia observed in substantive earlier research and supported by this present study, resistance band physical activity can be recommended as a potential therapy for people with dementia. The physical activity offered as a part of this study only took a short amount of time, was accessible for all abilities and could be performed at varying intensities.
This was reflected in the positive response given by participants during data collection. Adherence to longer term physical activity has been highlighted throughout the literature as problematic [64]. The focal point of future research should therefore be to identify ways in which people with dementia can increase and maintain their engagement in physical activity, in order to slow cognitive decline, maintain activities of daily living and prolong the requirement for residential care.

\section{Acknowledgements}

The authors would like to thank and acknowledge the participants that gave their time to this research. There are no conflicts of interest to report.

\section{Funding}

This research was funded by Loughborough University and all authors equally contributed to this original article.

\section{References}

1. Sink KM, Holden KF, Yaffe K (2005) Pharmacological treatment of neuropsychiatric symptoms of dementia: $A$ review of the evidence. JAMA 293: 596-608.

2. Fonseca-Santos B, Gremiao MPD, Chorilli M (2015) Nanotechnology-based drug delivery systems for the treatment of alzheimer's disease. Int J Nanomedicine 10: 4981-5003.

3. Marston L, Nazareth I, Petersen I, Walters K, Osborn DP (2014) Prescribing of antipsychotics in UK primary care: A cohort study. BMJ open 4: e006135.

4. Azermai M (2015) Dealing with behavioral and psychological symptoms of dementia: A general overview. Psychol Res Behav Manag 8: 181.

5. Galimberti D, Scarpini E (2010) Treatment of alzheimer's disease: Symptomatic and disease-modifying approaches. Curr Aging Sci 3: 46-56.

6. Forbes D, Thiessen EJ, Blake CM, Forbes SC, Forbes $S$ (2015) Exercise programs for people with dementia. Cochrane Database Syst Rev.

7. Hernandez SS, Sandreschi PF, da Silva FC, Arancibia BA, da Silva R, et al. (2015) What are the benefits of exercise for Alzheimer's disease? A systematic review of the past 10 years. J Aging Phys Act 23: 659-668.

8. Bauman A, Merom D, Bull FC, Buchner DM, Fiatarone Singh MA (2016) Updating the evidence for physical activity: Summative reviews of the epidemiological evidence, prevalence, and interventions to promote "Active aging". Gerontologist 56: S268-S280.

9. Taylor ME, Lord SR, Brodaty H, Kurrle SE, Hamilton S, et al. (2017) A home-based, carer-enhanced exercise program improves balance and falls efficacy in community-dwelling older people with dementia. Int Psychogeriatr 29: 81-91.

10. Brett L, Traynor V, Stapley P (2016) Effects of physical exercise on health and well-being of individuals living with a dementia in nursing homes: A systematic review. J Am Med Dir Assoc 17: 104-116.

11. Laver K, Dyer S, Whitehead C, Clemson L, Crotty M (2016) Interventions to delay functional decline in people with dementia: A systematic review of systematic reviews. BMJ open 6: e010767. 
12. Groot C, Hooghiemstra AM, Raijmakers PGHM, Van Berckel BNM, Scheltens P, et al. (2016) The effect of physical activity on cognitive function in patients with dementia: A meta-analysis of randomized control trials. Ageing Res Rev 25: 13-23.

13. Karssemeijer EGA, Aaronson JA, Bossers WJ, Smits T, Rikkert MGM, et al. (2017) Positive effects of combined cognitive and physical exercise training on cognitive function in older adults with mild cognitive impairment or dementia: A meta-analysis. Ageing Res Rev 40: 75-83.

14. Hogervorst E, Oliveira D, Brayne C (2018) New developments in dementia prevention research: State of the art and future possibilities. Lifestyle factors and dementia.

15. Liu-Ambrose T, Nagamatsu LS, Graf $P$, Beattie BL, Ashe $M C$, et al. (2010) Resistance training and executive functions: A 12-month randomized controlled trial. Arch Intern Med 170: 170-178.

16. Smith PJ, Blumenthal JA, Hoffman BM, Cooper H, Strauman TA, et al. (2010) Aerobic exercise and neurocognitive performance: A meta-analytic review of randomized controlled trials. Psychosom Med 72: 239-252.

17. Van Uffelen JG, Chin Paw MJ, Hopman-Rock M, van Mechelen W (2008) The effects of exercise on cognition in older adults with and without cognitive decline: A systematic review. Clin J Sport Med 18: 486-500.

18. Hsu CL, Best JR, Davis JC, Nagamatsu LS, Wang S, et al. (2017) Aerobic exercise promotes executive functions and impacts functional neural activity among older adults with vascular cognitive impairment. Br J Sports Med 52: 184191.

19. Ahlskog JE, Geda YE, Graff-Radford NR, Petersen RC (2011) Physical exercise as a preventive or diseasemodifying treatment of dementia and brain aging. Mayo Clin Proc 86: 876-884.

20. Mavros Y, Gates N, Wilson GC, Jain N, Meiklejohn J, et al. (2017) Mediation of cognitive function improvements by strength gains after resistance training in older adults with mild cognitive impairment: Outcomes of the study of mental and resistance training. J Am Geriatr Soc 65: 550-559.

21. Stamatakis E, Lee IM, Bennie J, Freeston J, Hamer M, et al. (2017) Does strength promoting exercise confer unique health benefits? A pooled analysis of 11 population cohorts with all-cause, cancer, and cardiovascular mortality endpoints. Am J Epidemiol 187: 1102-1112.

22. Brill PA, Drimmer AM, Morgan LA, Gordon NF (1995) The feasibility of conducting strength and flexibility programs for elderly nursing home residents with dementia. Gerontologist 35: 263-266.

23. Shakeel S, Newhouse I, Malik A, Heckman G (2015) Identifying feasible physical activity programs for long-term care homes in the ontario context. Can Geriatr J 18: 73104.

24. Gluchowski A, Warbrick I, Oldham T, Harris N (2018) 'I have a renewed enthusiasm for going to the gym': What keeps resistance-trained older adults coming back to the gym? Qualitative Research in Sport, Exercise and Health 10: $333-345$.

25. Kulmala J, Nykänen I, Mänty M, Hartikainen S (2014) Association between frailty and dementia: A populationbased study. Gerontology 60: 16-21.

26. Chang YK, Labban JD, Gapin JI, Etnier JL (2012) The effects of acute exercise on cognitive performance: A metaanalysis. Brain Res 1453: 87-101.
27. Scherder E, Scherder R, Verburgh L, Königs M, Blom $M$, et al. (2014) Executive functions of sedentary elderly may benefit from walking: A systematic review and metaanalysis. Am J Geriatr Psychiatry 22: 782-791.

28. Audiffren M, Tomporowski PD, Zagrodnik J (2008) Acute aerobic exercise and information processing: Energizing motor processes during a choice reaction time task. Acta Psychol 129: 410-419.

29. Coles K, Tomporowski PD (2008) Effects of acute exercise on executive processing, short-term and long-term memory. J Sports Sci 26: 333-344.

30. Hillman $\mathrm{CH}$, Pontifex MB, Raine LB, Castelli DM, Hall EE, et al. (2009) The effect of acute treadmill walking on cognitive control and academic achievement in preadolescent children. Neuroscience 159: 1044-1054.

31. Ludyga S, Gerber M, Brand S, Holsboer-Trachsler E, Pühse $U$ (2016) Acute effects of moderate aerobic exercise on specific aspects of executive function in different age and fitness groups: A meta-analysis. Psychophysiology 53: 1611-1626.

32. Drollette ES, Scudder MR, Raine LB, Moore RD, Saliba BJ, et al. (2014) Acute exercise facilitates brain function and cognition in children who need it most: An ERP study of individual differences in inhibitory control capacity. Dev Cogn Neurosci 7: 53-64.

33. Sibley BA, Beilock SL (2007) Exercise and working memory: An individual differences investigation. J Sport Exerc Psychol 29: 783-791.

34. Knaepen K, Goekint M, Heyman EM, Meeusen R (2010) Neuroplasticity-exercise-induced response of peripheral brain-derived neurotrophic factor: A systematic review of experimental studies in human subjects. Sports Med 40: 765-801.

35. Van Praag $\mathrm{H}$ (2008) Neurogenesis and exercise: Past and future directions. Neuromolecular Med 10: 128-140.

36. Lazarov O, Mattson MP, Peterson DA, Pimplikar SW, van Praag $\mathrm{H}$ (2010) When neurogenesis encounters aging and disease. Trends Neurosci 33: 569-579.

37. Kerr AL, Swain RA (2011) Rapid cellular genesis and apoptosis: Effects of exercise in the adult rat. Behav Neurosci 125: 1-9.

38. Adlard PA, Perreau VM, Cotman CW (2005) The exerciseinduced expression of BDNF within the hippocampus varies across life-span. Neurobiol Aging 26: 511-520.

39. Swain RA, Harris AB, Wiener EC, Dutka MV, Morris HD, et al. (2003) Prolonged exercise induces angiogenesis and increases cerebral blood volume in primary motor cortex of the rat. Neuroscience 117: 1037-1046.

40. Stimpson NJ, Davison G, Javadi AH (2018) Joggin' the noggin: Towards a physiological understanding of exerciseinduced cognitive benefits. Neurosci Biobehav Rev 88: 177-186.

41. Belarbi K, Rosi S (2013) Modulation of adult-born neurons in the inflamed hippocampus. Front Cell Neurosci 7: 145.

42. Sexton CE, Betts JF, Demnitz N, Dawes H, Ebmeier KP, et al. (2016) A systematic review of MRI studies examining the relationship between physical fitness and activity and the white matter of the ageing brain. Neuroimage 131: 81-90.

43. Tamura M, Nemoto $K$, Kawaguchi $A$, Kato M, Arai T, et al. (2015) Long-term mild-intensity exercise regimen preserves prefrontal cortical volume against aging. Int $\mathrm{J}$ Geriatr Psychiatry 30: 686-694. 
44. Firth J, Stubbs B, Vancampfort D, Schuch F, Lagopoulos $\mathrm{J}$, et al. (2018) Effect of aerobic exercise on hippocampal volume in humans: A systematic review and meta-analysis. Neuroimage 166: 230-238.

45. Voss MW, Vivar C, Kramer AF, van Praag H (2013) Bridging animal and human models of exercise-induced brain plasticity. Trends Cogn Sci 17: 525-544.

46. Folstein MF, Folstein SE, McHugh PR (1975) "Mini-mental state": A practical method for grading the cognitive state of patients for the clinician. J Psychiatr Res 12: 189-198.

47. Arcoverde C, Deslandes A, Moraes H, Almeida C, Araujo NBD, et al. (2014) Treadmill training as an augmentation treatment for alzheimer's disease: $A$ pilot randomized controlled study. Arq Neuropsiquiatr 72: 190-196.

48. Bossers WJ, van der Woude LH, Boersma F, Hortobágyi T, Scherder EJ, et al. (2015) A 9-week aerobic and strength training program improves cognitive and motor function in patients with dementia: A randomized, controlled trial. Am J Geriatr Psychiatry 23: 1106-1116.

49. McCarthy D (1972) McCarthy scales of children's abilities. Psychological Corporation.

50. Toots A, Littbrand H, Boström G, Hörnsten C, Holmberg $\mathrm{H}$, et al. (2017) Effects of exercise on cognitive function in older people with dementia: A randomized controlled trial. J Alzheimers Dis 60: 323-332.

51. Steinberg M, Leoutsakos JMS, Podewils LJ, Lyketsos CG (2009) Evaluation of a home-based exercise program in the treatment of alzheimer's disease: The Maximizing Independence in Dementia (MIND) study. Int J Geriatr Psychiatry 24: 680-685.

52. Brandt J (1991) The hopkins verbal learning test: Development of a new memory test with six equivalent forms. Clinical Neuropsychologist 5: 125-142.

53. Van der Wardt V, Bandelow S, Hogervorst E (2011) Development of the Cognitive Computerized Test Battery for Individuals with Intellectual Disabilities (CCIID) for the classification of athletes with intellectual disabilities. Nova Science Publishers.

54. Elliott-King J, Shaw S, Bandelow S, Devshi R, Kassam S, et al. (2016) A critical literature review of the effectiveness of various instruments in the diagnosis of dementia in adults with intellectual disabilities. Alzheimers Dement 4: 126-148.

55. Elliott-King J, Shaw S, Bandelow S, Hiremath A, Velayudhan L (2019) Dementia in individuals with intellectual disability; is there a better way to diagnose? Archives of Applied Medicine 1: 1-23.

56. Willardson JM (2018) Developing the core. Human Kinetics.

57. Kahle N, Tevald MA (2014) Core muscle strengthening's improvement of balance performance in communitydwelling older adults: A pilot study. J Aging Phys Act 22: 65-73.

58. Rogers SD, Jarrott SE (2008) Cognitive impairment and effects on upper body strength of adults with dementia. $J$ Aging Phys Act 16: 61-68.

59. Ades PA, Ballor DL, Ashikaga T, Utton JL, Nair KS (1996) Weight training improves walking endurance in healthy elderly persons. Ann Intern Med 124: 568-572.

60. Fountoulakis $\mathrm{KN}$, Tsolaki M, lacovides A, Yesavage J, O'Hara R, et al. (1999) The validation of the short form of the Geriatric Depression Scale (GDS) in Greece. Aging 11: 367-372.

61. Wolinsky FD, Unverzagt FW, Smith DM, Jones R, Wright E, et al. (2006) The effects of the ACTIVE cognitive training trial on clinically relevant declines in health-related quality of life. J Gerontol B Psychol Sci Soc Sci 61: S281-S287.

62. Samus QM, Black BS, Bovenkamp D, Buckley M, Callahan C, et al. (2018) Home is where the future is: The brightfocus foundation consensus panel on dementia care. Alzheimers Dement 14: 104-114.

63. Clarkson P, Hughes J, Xie C, Larbey M, Roe B, et al. (2017) Overview of systematic reviews: Effective home support in dementia care, components and impacts-stage 1, psychosocial interventions for dementia. J Adv Nurs 73: 2845-2863.

64. van der Wardt V, Hancox J, Gondek D, Logan P, Nair R, et al. (2017) Adherence support strategies for exercise interventions in people with mild cognitive impairment and dementia: A systematic review. Prev Med Rep 7: 38-45. 